\title{
Technological Advances in Accelerated Wound Repair and Regeneration
}

\author{
Xanya Sofra ${ }^{1}$, Nuris Lampe $^{2}$ \\ ${ }^{1}$ Research and Technology Development, IELLIOS Ltd., Ipwsich, UK \\ ${ }^{2}$ Clinical Dermatology Department of Horatio Oduber Hospital, Oranjestad, Aruba \\ Email: science@iellios.com,nurisvita@gmail.com
}

How to cite this paper: Sofra, X. and Lampe, N. (2020) Technological Advances in Accelerated Wound Repair and Regeneration. Health, 12, 717-737.

https://doi.org/10.4236/health.2020.127053

Received: June 3, 2020

Accepted: July 3, 2020

Published: July 6, 2020

Copyright (c) 2020 by author(s) and Scientific Research Publishing Inc. This work is licensed under the Creative Commons Attribution International License (CC BY 4.0).

http://creativecommons.org/licenses/by/4.0/

\begin{abstract}
We reviewed a number of wound repair, keloid and hypertrophic scar research methods that included lasers, microcurrent and ultra-low energy technologies. Laser research reports short-term improvement in wounds, keloid and hypertrophic scars, but without follow up to control for reoccurrence of keloids or diabetic lesions which generally reoccur following laser treatments. The microcurrent and ultra-low energy studies demonstrate significant healing where age is not a factor with no reoccurrence of diabetic wounds and other skin lesions. Our randomized, double-blind longitudinal research on eight wound repair clinical cases with an age range of $28-86$, followed for one year, evidenced accelerated healing and no reoccurrence. The number of treatments required for substantial healing depended on the chronicity and severity of the lesion, with chronic severe lesions requiring more treatments, rather than age, a conclusion supported by ultra-low microcurrent research. These results on age-independent wound healing directly contradict a large body of literature postulating that healing is much slower with age due to immune insufficiency, age-accumulated oxidative stress, disrupted cell communications and sustained inflammation.
\end{abstract}

\section{Keywords}

Keloids, Acute Wounds, Hypertrophic Scars, Inflammation, Eschar Wounds, Herpes Zoster, Aging, Wound Healing, Diabetic Lesions

\section{Introduction}

The skin responds to injury with a series of dynamic processes that can be summarized into three phases: 1) coagulation/inflammation, 2) tissue formation and 3) remodeling. Fibrotic scarring, the pathological wound healing in which connective tissue undergoes extensive remodeling prior to replacing normal paren- 
chymal tissue, leads to keloids when keratinocyte signals are damaged. Skin gamma delta $\mathrm{T}$ cells $(\gamma \delta \mathrm{T})$ appear to emit signal warnings about keratinocyte damage and release key growth factors [1]. Growth factors such as transforming growth factor $\beta$ (TGF- $\beta$ ), epidermal growth factor (EGF), fibroblast growth factor (FGF) and platelet-derived growth factor (PDGF) are involved in the excessive deposition of collagen in the dermis and subcutaneous tissues often resulting in keloid and hypertrophic scars [2]. Inflammation is present in adult but not embryonic wounds that heal without a scar, suggesting that inflammation may be partly responsible for scarring along with faulty signaling such as inactivation of the small GTPase Rho that inhibits re-epithelization and Cdc42 that is involved in the wound adhesion process [3]. Wound healing gene expressions include Ap1, Fos and Jun genes, and the krox zinc finger transcription factors that appear to activate the upregulation of hundreds of genes involved in cellular proliferation and epidermal migration between the scab and the healthy wound granulation tissue. Some of these genes are silenced until the PcG genes are downregulated after the wounding process [4] [5]. Inflammation and fibrosis appear to go hand in hand, both related to an overactivity in signaling communications involving the fibroblast-specific focal adhesion kinase (FAK) that acts through the extracellular-related kinase (ERK) to trigger the secretion of the monocyte chemoattractant protein-1 (MCP-1), since knockout of FAK and MCP-1 appears to inhibit both inflammation and pathologic scar formation [6]. Mesenchymal stem cells appear to be involved in wound repair by transdifferentiating into various skin cells such as keratin 14-positive cells, keratinocytes, endothelial cells and pericytes [7]. Technologies utilized to speed up the healing process include different forms of photo biomodulation such as ultrasound and lasers, electrical stimulation, electromagnetic fields and ultra-low microcurrent interventions.

\section{Dysregulated Signaling Pathways and Persistent Inflammation Underlie Abnormal Healing}

An overlook of the complex landscape of wound healing processes offers at least two therapeutic targets, reducing persistent inflammation and reinstating balance in damaged or over-excited signalling networks. Initially, hemostasis rapidly follows injury involving platelet-plug formation to reduce blood loss and prevent contamination. Inflammation first recruits, neutrophils, the phagocyte white blood cells (WBC), kill invasive microorganisms at the wound site. Macrophages clear apoptotic neutrophils and develop early wound closure events [8]. Recent knockout and knockdown studies suggest that depletion of one or more of the inflammatory cell lineages enhance healing [9]. During the inflammatory phase, mast cells release histamine and other substances that ultimately result in scar formation. Entirely normal healing is observed at the genetic depletion of mast cells [10]. Moreover, embryonic model studies on wound healing have indicated that prior to the onset of a wound inflammatory response, im- 
mature tissues are capable of scar-free healing [11] [12]. Activation of the chemokine ligand 2 release by wound fibroblasts draws in a larger inflammatory response while locking the release of chemokine ligand 2 leads to reduced inflammation and subsequently reduced scarring [13]. Chronic, persistent inflammation is a hallmark of most chronic wounds. On the other hand, resolution of the inflammatory response is the normal pathway that biological mechanisms take during accelerated healing [14]. Keloids are characterized by occluded blood vessels, they are non-regressive and extend beyond the margins of the original tissue [15]. Interestingly, keloids tend to show a genetic predisposition, mainly associated with darker-skinned populations [16] [17]. In terms of systemic risk factors, adolescence and pregnancy appear to be associated with a greater risk of developing pathological scars, presumably due to the vasodilatory effects of hormonal imbalance involving sex hormones such as estrogens and androgens [18].

In conclusion, this research data supports the theory that unbalanced signalling including hormonal imbalance, where certain processes are disrupted, and others are overstated, increases scarring. On the basis of this reasoning, hypertrophic and keloid scars may be the result of a combination of inflammation and aberrant over-activity of wound fibroblasts, cytokines and other signalling proteins, kinases and growth factors that is not switched off but aimlessly continues after the wound repair process has been completed, i.e. a dysregulated signalling issue.

\section{Laser Efficiency on Wounds Keloids and Hypertrophic Scars}

Laser devices used in the treatment of keloids and hypertrophic scars are mostly based on the principle of selective photo thermolysis which involves a specific wavelength light emitted by the laser acting on a target skin structure to either remove part or all the tissues on which the laser is applied (ablative lasers) or induce necrosis of these skin structures without, however, removing them (non-ablative lasers) [19]. However, different skin structures respond differently to eradication which requires high level of expertise and often has adverse side effects. A plethora of laser research is based on subjective treatment outcome evaluation, limited or no follow-up, and poor study design [20]. Follow up is crucial in light of evidence that keloid reoccurrence is more frequent in some skin structures more than others after laser treatments [21] [22]. Other laser research claims statistical significance that is not convincing when the results are subjected to critical analysis. For example, study with 22 subjects receiving ND:YAG laser irradiation reported a statistically significant improvement of $\mathrm{p}<$ 0.01 on the subjects' keloids and hypertrophic scars [23]. A statistical significance of $\mathrm{p}<0.01$ indicates that over $99.9 \%$ of the subjects were benefited by the treatment. However, upon more careful examination of the study, only 8 out of $22(36 \%)$ subjects had a clear reduction in the size of their lesions, 10 of these 
subjects had a slight reduction (45\%) and 4 (18\%) showed no change.

5 -FU technology has been shown in-vitro to reduce fibroblast growth and increase fibroblast apoptosis while decreasing collagen synthesis [24]. However, 5-FU has side effects such as wound ulceration, and hyperpigmentation and offers results that are not statistically significant since only $66 \%-77 \%$ of patients experience greater than $70 \%$ scar flattening, with $21 \%$ - 35\% recurrent rate [25] [26]. Low-level laser therapy (LLLT) was found to significantly decrease the time of wound healing of 68 patients with foot ulcers due to Diabetes Mellitus (DM) [27]. This study was not longitudinal therefore, the incidence of reoccurrence is unknown. Beckerman et al. looked at the efficacy of laser therapy on skin disorders on the basis of 36 randomized clinical trials involving 1704 patients. The laser studies that report significant improvement in treated wounds do not follow up to assess the possibility of re-occurrence. Beckerman et al. conclude that the efficacy of laser therapy on skin lesions is unclear or undetermined [28].

\section{Endogenous Electrical Fields in Wound Healing and Ultra Low Energy Devices}

Endogenous electrical fields (EF) arise instantaneously during skin injury, enhancing cell proliferation. Chemically enhancing endogenous EF increases cellular proliferation in the first $200-600 \mu \mathrm{m}$ from the wound site, and chemically reducing the endogenous EF decreases cell division especially in the first $200 \mu \mathrm{m}$ from the wound site. Chemically enhancing endogenous EF also increases the polarization index at the wound site, while chemically reducing the woundgenerated EF reduces the polarization index almost to zero. Moreover, EF disruption causes specific abnormalities of CNS development [29].

During wound healing, angiogenic capillary sprouts invade the fibrin/fibronectin-rich wound clot developing a microvascular network throughout the granulation tissue. As collagen accumulates in the granulation tissue to produce a scar, the density of blood vessels diminishes. A number of research articles report that electrical stimulation enhances angiogenesis that is directly related to wound generated endogenous EF [30] [31]. There is evidence that injured tissue becomes electrically polarized by endogenous EF relative to surrounding normal tissue. When physiological EF with the above parameters are applied in-vitro to cells in culture, they appear to determine the orientation, the migration and the axis of division of epithelial cells [32].

Several microcurrent studies have reported enhancing soft tissue healing, increased secretion of growth factors and adenosine triphosphate (ATP) production [33] [34] [35]. Poltawski and Watson 2013 [36] examined a large number of all peer-reviewed studies on the effects of ultra-low microcurrent in tissue healing at intensities similar to those produced by the body and concluded that microcurrent therapy can promote healing in a variety of bone and skin lesions. Wirsing et al. (2013) [37] studied 47 patients with hard-to-heal venous, arterial and mixed leg ulcers treated with $1.5 \mu \mathrm{A}$ current intensity and found a mean reduction of the wound surface in $95 \%$ of the cases with complete healing achieved 
within three months for the majority of the cases with no clinical side effects.

Bok Lee et al. [38] reported that ultra-low microcurrent has notable age-independent therapeutic effects on diabetes, hypertension and wound healing. They used an electrical device that delivers a direct current that ranges from 3 $\mathrm{mA}(1 \mathrm{~mA}=0.001 \mathrm{Amp})$ down to 100 nanoamperes (1 nanoampere $=10^{-9} \mathrm{am}$ peres) and a voltage ranging from $5 \mathrm{~V}$ up to a maximum of $40 \mathrm{~V}$. They postulated that the steady stream of electrons emitted by their device into the skin acts as a super antioxidant because this steady electron stream delivery amounts to more electrons entering the skin, versus the interrupted mode of electron delivery adopted by TENS devices. Bok Lee et al. interpreted the age-independent wound healing as an intervention on oxidative damage where ultra-low microcurrents act as a potent antioxidant reducing inflammation. Mitochondrial oxidative metabolism necessary for energy production produces reactive oxygen species (ROS) and organic peroxides. Energy production is necessary for cell homeostasis, signal transduction, gene expression, receptor activation, etc. [39] [40]. Infections and injuries trigger an immune activity that needs to be powered by extra energy leading to an overproduction of ROS causing oxidative stress probing the expression of genes involved in inflammatory pathways along with the synthesis and secretion of proinflammatory cytokines, inevitably leading to chronic inflammation [41].

Electron donation by anti-oxidants transforms free radicals into stable molecules, an interesting time-reversal operation observed only with simple molecular mechanisms that are non-applicable to complex entities. Complex entities like vital organs, for example, are composed of stable intertwined cellular structures determined by early stem cell differentiation processes that transform them into Gestalts. Gestalts are characterized by idiosyncratic qualities not present in the constitution of their parts. The reason why damaged organs cannot spontaneously go back in time, and transform into the healthy state of their previous existence, is because Gestalt entities are not merely the sum total of the cells that compose them, but unique entities, a liver, a heart, a kidney, each with a life of its own that cannot be reduced back into the cells that originally composed it without losing its most important component, the specificity of the Gestalt that defines it and distinguishes it from other organs. The current research used a new ultra-low energy nanotechnology based on three theoretical principles.

Principle 1. Electron Gated Ion Channels at Energies below Thermal Noise

While strong oscillating electromagnetic fields have shown no easily measurable or obvious effects on humans or living systems, much weaker oscillating fields have been shown to affect living systems in often dramatic ways [42]. In his book "Electron Gated Ion Channels" Wilson Ranston [43] presents a new quantum-mechanical approach to the intrinsic simplicity of electrons controlling sodium, potassium and calcium ion channels at ultra-low energies below thermal noise, elucidating mechanisms important to cellular function and signalling. 


\section{Principle 2. Time Reversal Is Only Possible in Molecular Mechanisms}

The possibility of time reversal increases with simplicity and decreases with complexity. Simple molecular mechanisms like free radicals can go back in time and reinstate themselves as stable molecules as a result of anti-oxidant electron donation. This time reversal process can be observed with AMP being transformed forward into ADP and ATP, and backwards into ADP and AMP with the simple addition or subtraction of a phosphate. Similar time reversal processes can be observed with $\mathrm{G}$ proteins and several other microscopic biological mechanisms. Time reversal becomes impossible with increasing complexity because as cells combine to form organs or whole entities they turn into Gestalts that persist despite changes that may occur in their parts. This molecular time-reversal process has recently driven a number of Nobel Prize winning research [44]-[49].

Principle 3. Cells' Communications Reflect Intertwined Dynamic Networks with Predictable and Unpredictable aspects

The Nobel Prize in Physiology or Medicine 2013 [50] describes transport and delivery of cellular signals resembling a public transport system. Defective signal transport occurs in a variety of diseases including a number of neurological and immunological disorders, as well as in diabetes [51]-[56]. Within the nervous system, neurons transmit information via electrical signals limited to their physical connectivity, acting like telephone landlines, while glial cells involve a wider range of cell signalling processes via $\mathrm{Ca}^{2+}$ concentrations in the cytosol, acting like cell phones [57]. Chaban et al. demonstrated that cells can also engage in cell-to-cell signalling in the absence of physical contact between them, demonstrating physically disconnected, non-diffusible cell-to-cell communications [58].

The cellular signalling communication network can be seen as a microcosmos reflecting traffic events that are divided into predetermined predictable events such as traffic lights and non-predictable events that emanate from the variety of car types, car conditions, speed, drivers and driving styles. Research to date has mostly provided knowledge for predictable events with an increasingly sophisticated yet limited, dynamic volatility confined by the traditionally recognized signalling pathways. Chaban's et al. findings [58] on the persistence of neuronal communications beyond barriers unveil a vast dynamic uncertainty of the biological communications network that may behave differently under unforeseeable circumstances. This precarious dynamic variability warrants the necessity of longitudinal studies before drawing conclusions on the efficacy of any technology presented in the treatment of wounds or any other disorder.

\section{Methodology}

We utilized an ultra-low energy nanotechnology, originally invented in London University in 1992 and subsequently modified over a period of 20 years on the basis of unpublished in vitro, clinical and electronic research. The technology 
has been used for over 10 years in clinical practice by over 800 physicians around the world with no reported adverse reactions or sides effects. It is subjectively experienced as relaxing despite the fact that it is imperceptible. Contraindications, warnings and cautions are according to the list provided under TENS devices by the FDA, although the technology's nanoamp output (nanoamp = $10^{-9}$ Amperes) that reaches the skin ranges from $10-60$ nanoamps that is substantially lower than the milliamp range (milliamp $=10^{-3}$ Amperes) of TENS devices. The technology stores 9600 sine and square waveforms synthesized on the basis of an original mathematical formula with resultant frequencies ranging from $0.25-10,000 \mathrm{~Hz}$. The waveforms are delivered through the skin by voltage that ranges from $0.003 \mu \mathrm{V}$ to $0.5 \mu \mathrm{V}\left(\mu \mathrm{V}=10^{-6}\right.$ Volts) depending on the resultant frequency. The 9600 waveforms are emitted in a sequence determined by a second prototypical mathematical formula at variable time intervals determined by a third original mathematical formula. The technology is designed to emit four resonant complex waveforms simultaneously in a variety of discrete specific times that range from 4 secs to 24 secs via the technology's single physical channel and through a pair of tour grade ultra-silver-plated microphone cables with stainless surgical steel probes attached to their ends that must make contract with the subject's skin. Leads are sanitized prior to each usage. The device has been classified as an IEC class I according to the IEC60601-1 standard and complies with the EEC UK directions of electrical equipment safety applied standard EN60601-1. It is used with 3-pin din and 4-pin din IEC 60601-1 compliant cables. It has a CE marketing directive of Class I with electromagnetic compatibility regulations applied standards EN50081-1 and EN50082-1. The only contraindications are pacemaker or other implanted electronic devices, and the only caution is pregnancy, according to the FDA regulations for electrical devices.

\section{Procedure}

Eight subjects, one male and 7 females, 28 - 84 years of age, one Caucasian, 4 Hispanic and 3 Chinese were included in this clinical trial. Subjects were randomly selected out of 15 cases of wound healing cases treated by 4 independent clinicians in their private clinics, one in the US, one in Aruba and two in Hong Kong. All subjects signed consent forms for the release of their records including before and after photos. None of these clinicians had a bias or a personal interest in the direction of the results. The subjects were asked to relax while placing the metal probes of the technology directly onto the wounds. Since the technology is imperceptible without sensation, the subjects had no way of knowing whether the technology was on or off serving as their own controls. All subjects were followed for one year after treatment. All procedures were conducted by nurses who had basic knowledge on how to operate the technology. All subjects received the treatment after they completed a medical health questionnaire, a clinical interview conducted by a licensed clinician or licensed clinical dermatologist, and after they signed a comprehensive consent form agreeing to receive the 
treatment. None of the subjects was pregnant, had a cardiac pacemaker, implanted defibrillator or other implanted electronic device. Subjects' total number of treatments and photos, without identifying whether a picture was a before or an after or offering any other information, were e-mailed to three unbiased independent judges who practiced at different parts of the world, and were unfamiliar with the technology. Scoring was based on a scale from 1 to 10 with 1 signifying no healing and 10 signifying maximum accelerated healing. The judges e-mailed back the pictures with four scores: a before and after score on speed of healing and a before and after score on degree of healing.

Results:

Case 1. Traffic Accident Wound

This 39-year-old male scraped the skin and flesh off his right-hand knuckles during a car accident, losing the fingernails of his middle, ring and little fingers. The knuckle wounds of his index and middle fingers were $4 \mathrm{~mm}$ long, $3.5 \mathrm{~mm}$ wide and $3.75 \mathrm{~mm}$ deep respectively, exposing the bone under the phalanx of his index and middle fingers. Following the accident, he was admitted to the emergency room from where he was referred to a plastic surgeon who recommended plastic surgery, but warned the patient that he may never grow nails on his middle, ring and little finger or regain mobility of his hand. He then consulted a specialist who performed the low-energy nanotechnology treatment twenty-five days after his accident. Prior to his first treatment, he reported constant pain, increased inflammation, edema, and fever, despite taking oral antibiotics and treating the wound with an antibiotic cream. He received 12 treatments three times weekly for a month. Two weeks after the 12 th treatment his hand had completely healed. All damaged tissue was replaced by healthy skin without leaving a scar, he had full mobility of his hand and his nails were growing normally (Figure 1). The judges' mean average scores were: before treatment speed of repair (BTSR) 1.3: before treatment degree of repair (BTDR): 1.3; after treatment speed of repair (ATSR) 7.6; after treatment degree of repair (ATDR): 9.6.

\section{Case 2. Knife Cut Accident}

Female 53-year-old with a deep knife cut wound on her finger. The wound was $1.2 \mathrm{~cm}$ long and $3 \mathrm{~mm}$ deep. She experienced excessive bleeding and went to the emergency room where the wound was stitched. The day after she received the low-energy nanotechnology treatment by her dermatologist. She had four 20-min treatments twice weekly for two weeks. Immediately after the first treatment, the inflammation around the stitches was diminished as seen in the second picture of Figure 2. The morning after the second treatment, the patient reported that she was able to move her finger without experiencing pain. After the fourth treatment ten days later, the wound had completely healed leaving a flat scar (Figure 2). The mean average scores were: BTSR: 3.3. BTDR: 4.6; ATSR: 7.6; ATDR: 6.3.

Case 3. Diabetic Foot Ulcers

Female 84-year-old with diabetic ulcers, neuropathy, and lower limp lymphe- 
dema. Diabetic foot ulcers do not adhere to the cellular and molecular events involved in the healing of acute wounds. Ulcer wound fibroblasts are usually senescent, have diminished migratory capacity, and do not respond to growth factor signals, as is reflected in the dramatically reduced levels of TGF- $\beta$ receptors. Immune cells' signalling is disrupted demonstrating reduced phagocytic and bactericidal activities. There is generally necrotic debris and a heavy inflammatory infiltrate, particularly of neutrophils that may be phenotypically different from their equivalents in healing acute wounds [59] [60]. Peripheral limb edema is a feature of diabetes that has been identified as a significant risk factor for amputation in patients with diabetic foot ulcers [61]. The diabetic ulcers was 4.5 $\mathrm{mm}$ deep, $2 \mathrm{~cm}$ wide and $2 \mathrm{~cm}$ long. She had been unresponsive to antibiotic medication and other traditional wound treatments that she had in the past. She received six 30-min treatments once a week for six weeks. Epithelial cells at the edge of a wound appeared to proliferate after the third treatment and the edema was significantly reduced. Epithelialization appeared to occur from within the wound and after the $4^{\text {th }}$ treatment the wound appeared to close through the formation of granulation tissue. Reepithelialisation resulted in a wound contraction that reduced the diabetic lesion by $93 \%$ leaving some pinkish erythema around it. The third photo was taken a year later showing additional healing and no reoccurrence of the diabetic lesion (Figure 3 ). The mean average scores were: BTSR: 1; BTDR 1.3; ATSR 7.6; ATDR: 8.6.

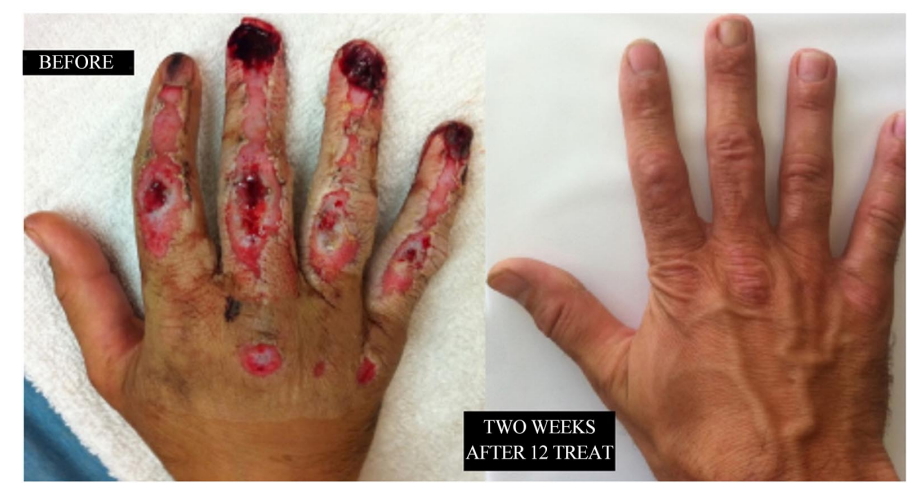

Figure 1. Traffic accident wound. Before treatment and two weeks after the $12^{\text {th }}$ treatment.

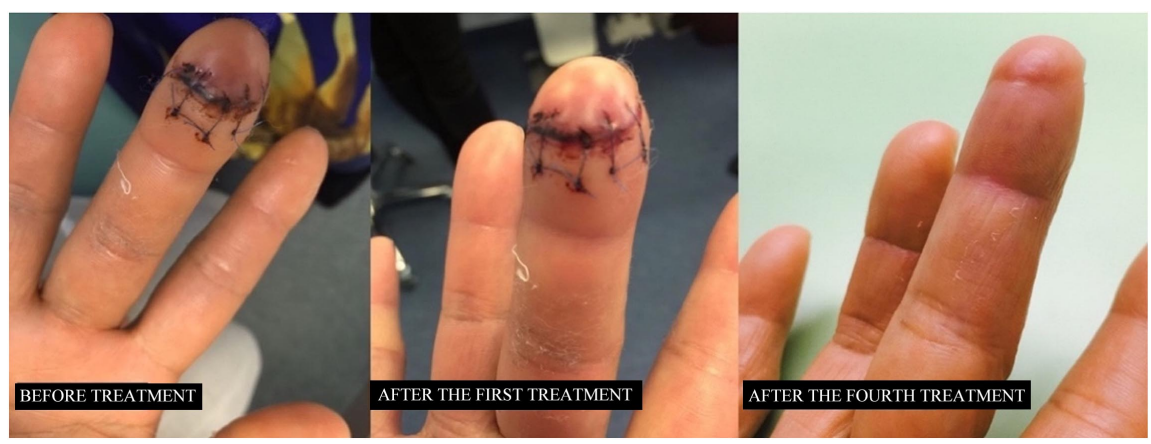

Figure 2. Before the first treatment, after the 1st treatment and the 4th treatment. 


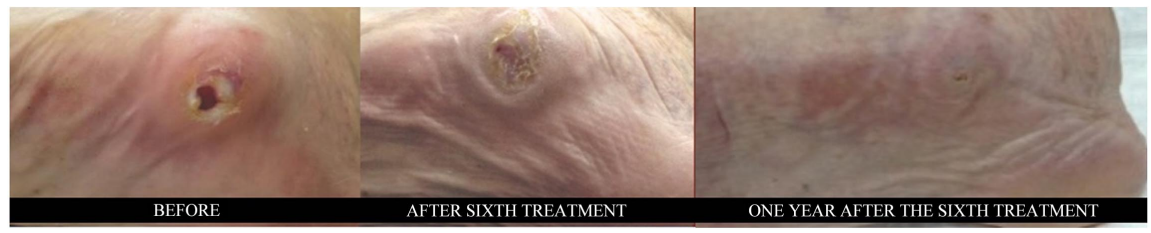

Figure 3. Diabetic foot ulcers. Before, after the $6^{\text {th }}$ treatment and one year after the $6^{\text {th }}$ treatment.

\section{Case 4. Necrotic Tissue Wound nine days after Liposuction Procedure}

This 39-year-old female was a non-smoker, with no reported previous medical conditions, complications or surgical procedures other than undergoing liposuction nine days prior to the nanotechnology treatment. As a result of the liposuction, she developed a necrotic wound of the eschar type, $4 \mathrm{~mm}$ deep, $16 \mathrm{~cm}$ long and $8.5 \mathrm{~cm}$ wide. Prior to treatment the eschar wound was composed by black, dry, thick, leathery tissue. Normally, this type of tissue adheres to the wound and cannot be removed, significantly delaying wound healing unless the necrotic tissue is surgically removed.

Treatment was performed twice a week for 30 minutes, for 8 consecutive weeks, for a total of 16 sessions. After the $4^{\text {th }}$ treatment, the wound appeared to change into a slough lesion composed by a deeper area characterized by a combination of deep red and yellow-white tissue that was moist and stringy in appearance, and was surrounded by a more shallow thin pink outline of granulated tissue shown in picture 2 of Figure 4. Epithelialization appeared to progress from within the wound outwards, with new granulation tissue filling in the wound and connecting its edges as well as microscopic blood vessels forming on the surfaces of the granulated skin as shown in picture 3 of Figure 4. After the fourteenth treatment, the skin had the appearance of full thickness and was light pink in colour as in picture 4 of Figure 4 . The patient reported full skin recovery after a month following the sixteenth treatment with a flat faded scar, for which no photos were provided. The judges' mean average scores were: BTSR: 1; BTDR 1.3; ATSR 6.3; ATDR: 7.6.

\section{Case 5. Hypertrophic Scar after a 3-year-old Liposuction Wound}

This 39-year-old female developed a hypertrophic scar from a three-year-old liposuction procedure that initially left an eschar wound as in case 4 . The hypertrophic scar was $3.5 \mathrm{~mm}$ raised, erythematous and brownish-red in colour, 20 $\mathrm{cm}$ long and $4 \mathrm{~cm}$ wide, and it was surrounded by post-inflammatory hyperpigmentation that covered a large part of her waist, part of her abdomen and her backside. She received 1030 -min treatments twice a week over a period of 5 weeks. After the $10^{\text {th }}$ treatment the hypertrophic scar was almost completely reabsorbed and it was replaced by new tissue, leaving a faded flat scar of around $12 \mathrm{~cm}$ long and $0.8 \mathrm{~mm}$ wide. The pigmentations that previously covered her waist, part of the abdomen and backside had also significantly subsided (Figure 5). The patient reported no reoccurrence of the hypertrophic scar after one year. The mean average scores of the three judges were as follows: BTSR: 1; BTDR 1.3; ATSR 6.3; ATDR: 7.6. 


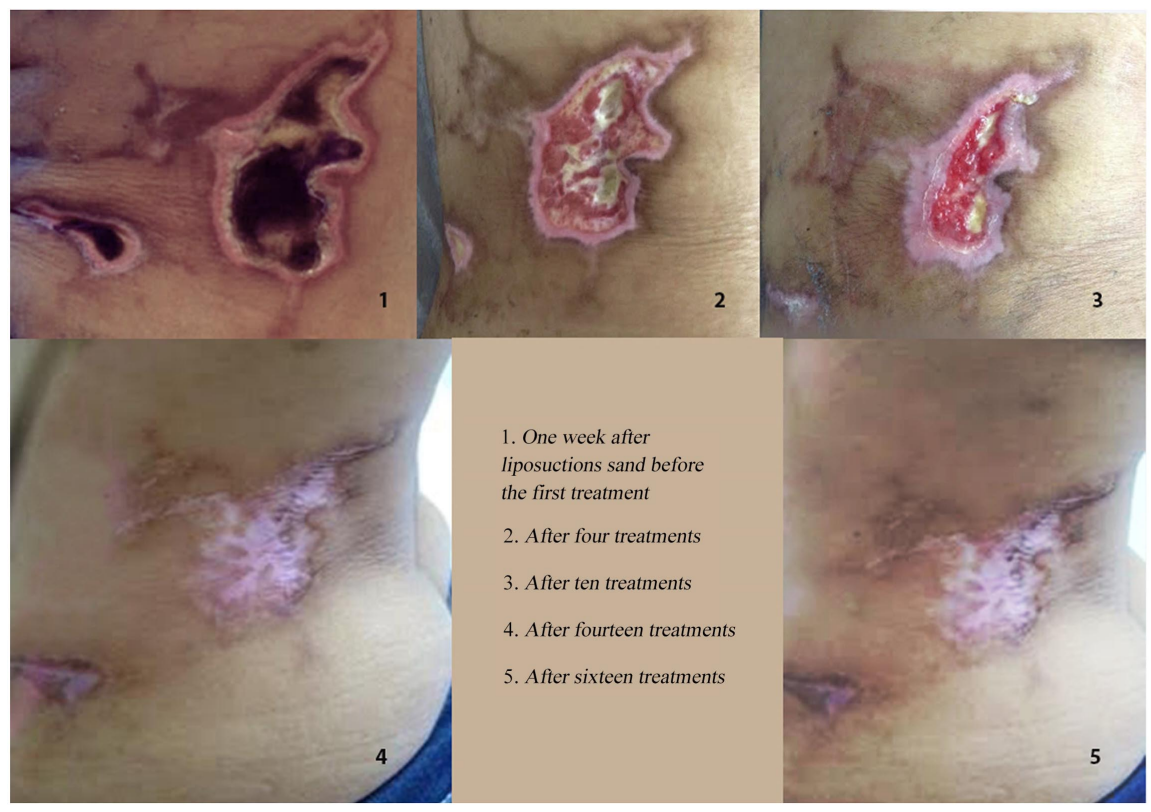

Figure 4. Necrotic Tissue Wound nine days after Liposuction Procedure. The progress of a deep necrotic wound healing, before treatment (1) and after four (2), eight (3), thirteen (4) and fourteen (5) treatments.

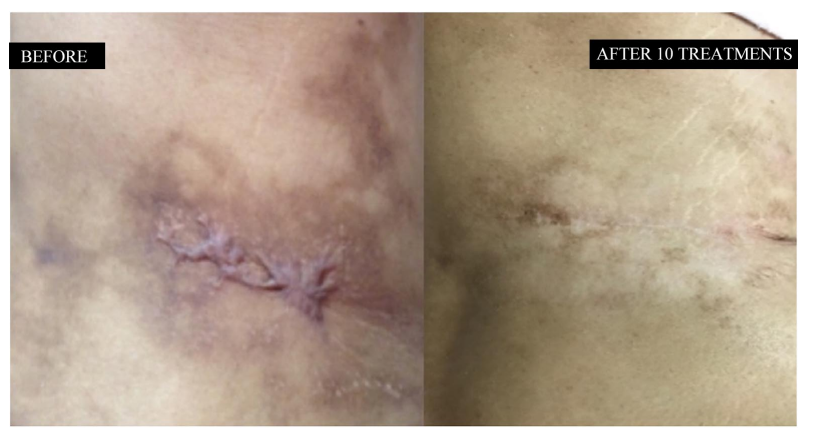

Figure 5. Hypertrophic scar surrounded by post-inflammatory pigmentation before and after 10 treatments.

\section{Case 6. Postoperative Wound after removal of Basal Cell Carcinoma}

Female patient 85-year-old with severe sun damage, chronic venous insufficiency and a history of basal cell carcinomas, a type of cancer developed in various areas of her body exposed to the sun, including face and legs. Patient was diagnosed with diabetes mellitus and neuropathy on both legs. The basal cell carcinomas on the side of her face were first surgically removed by her dermatologist leaving a large wound of $8 \mathrm{~cm}$ long and $3 \mathrm{~cm}$ wide and seven smaller wounds, ranging from $1 \times 2 \mathrm{~mm}$ to $2 \times 3 \mathrm{~mm}$ each. The patient was given six 30-min ultra-low energy nanotechnology treatments for six consecutive weeks. A reduction of both erythema inflammation as well as the wide-spread post-inflammatory pigmentations were observed immediately after the first treatment and the reparative process became progressively more evident as treatments progressed to the maturation phase, where the wound looked closed and repaired, while still healing. All wounds healed normally without evidence of scar- 
ring (Figure 6). The judges' mean average scores were: BTSR: 3.3: BTDR: 2.3; ATSR: 7.6; ATDR: 8.3 .

\section{Case 7. Herpes Zoster}

This 86-year-old female developed Herpes Zoster, a viral infection caused by the varicella-zoster virus. On the first week after experiencing pain, hyperesthesia, facial lesions, muscle weakness, and fever she went to the hospital where she was treated with antiviral medications including Amciclovir and Valacyclovir, anti-inflammatory corticosteroids and cool compressions to soothe the rash, with no significant improvement in her condition. She received two 40-min treatments with the ultra-low energy nanotechnology one week apart. Prior to treatment, she presented weakness of the right-side muscles of her face and her right eye was half-closed. Her right cheek and mouth were covered with extensive lesions. Both the cheek and mouth lesions completely cleared after the second treatment and her left and right side of her face appeared to be balanced. A week after the second treatment the pinkish skin inflammation had reportedly completely disappeared in the absence of any scar formation. There was no erythema or hyperpigmentation and the skin appeared normal (Figure 7). To date, 2 years and 4 months following the two treatments, there has been no reoccurrences of Herpes Zoster. The judges' mean average scores were: BTSR 1: BTDR: 2.3; ATSR: 9.3; ATDR: 8.3.

\section{Case 8. Second Degree Burn:}

This 28-year-old female got a second degree burn after accidently spilling hot boiling soup on her thighs. She went to the hospital for emergency care and then saw the doctor who offered her 4 ultra-low energy nanotechnology treatments over a period of two weeks. The day after the first treatment the patient reported extensive healing that became more visible two days after the first treatment. The post inflammatory pigmentation observed after the third treatment was reduced after the fourth treatment (Figure 8). The patient reported that two weeks after her four treatments the pigmentation was significantly lighter, and the skin of her thighs appeared to be normal, The judges' mean average scores were: BTSR 3.3; BTDR 2.3; ATSR: 8.3; ATDR: 7.6.

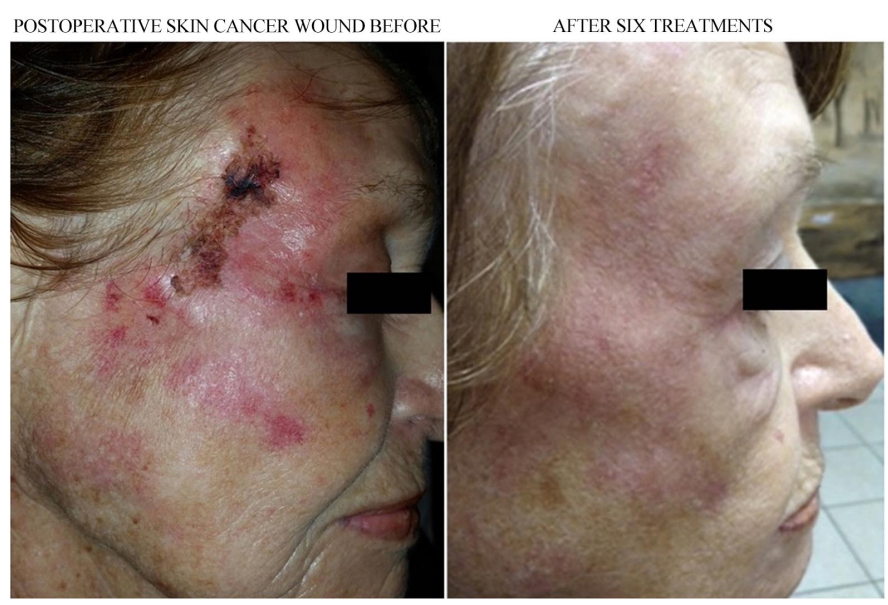

Figure 6. Postoperative wound prior to treatment and after six treatments. 


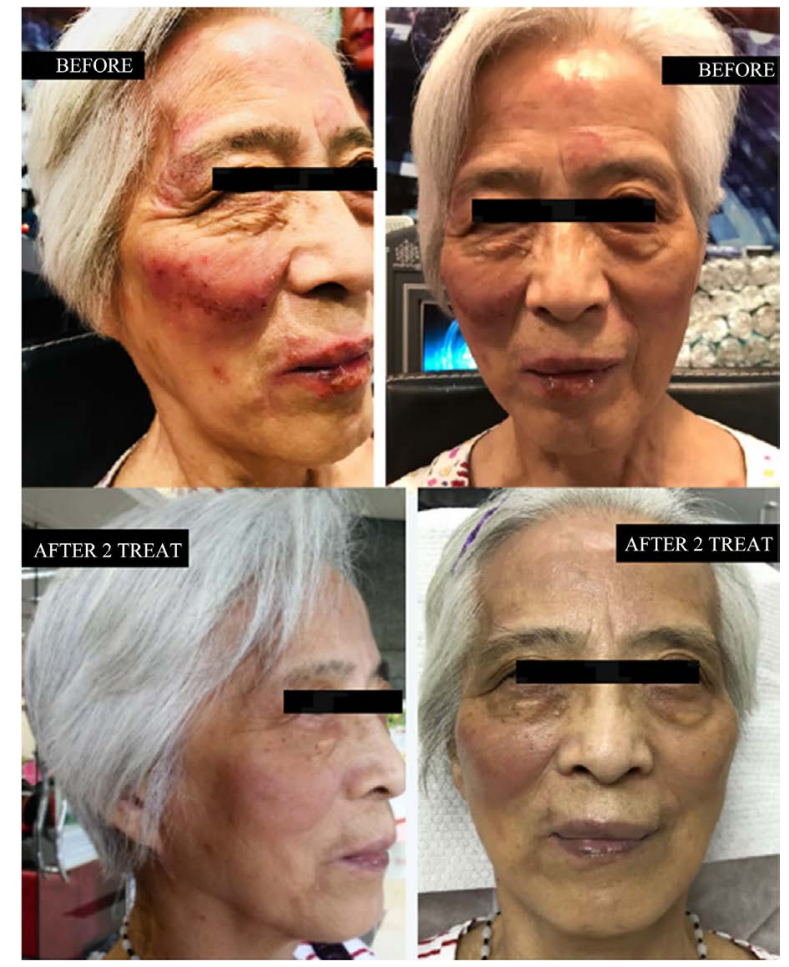

Figure 7. Herpes Zoster before and after two treatments.
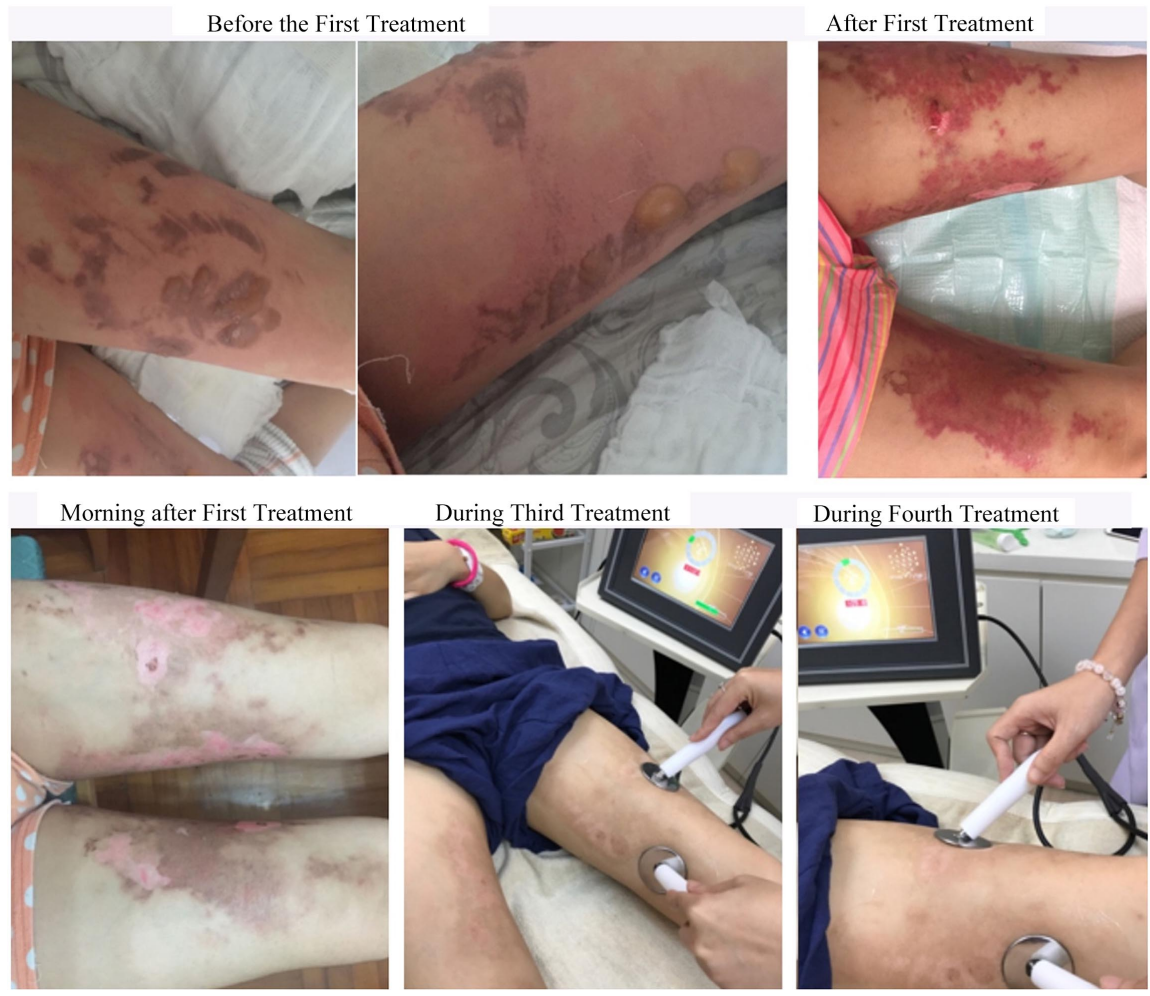

Figure 8. Second degree burn; healing progress from the $1^{\text {st }}$ to the $4^{\text {th }}$ treatment.

\section{Results Analysis}

The mean average of the three judges' scores for the 4 categories BTSR, BTDR, 
ATRS and ATDR are given in Table 1.

We performed the non-parametric Mann Whitney $U$ test that is more appropriate for an ordinal scale used by the three judges to rate the subjects' degree and speed of wound repair.

For the before and after speed of repair scores the U-value was 0 . The critical value of $U$ at $p<0.01$ was 9 , therefore the result was significant at $p<0.01$. The $\mathrm{z}$-score was -3.3816 . The $\mathrm{p}$-value $=0.00046$. The result was significant at $\mathrm{p}<0.01$ level. For the before and after degree of repair scores the U-value was 0 . The critical value of $U$ at $p<0.01$ was 9 , therefore the result was significant at $p<$ 0.01 . The $\mathrm{z}$-score was -3.30816 . The $\mathrm{p}$-value $=0.00047$. The result was significant at $\mathrm{p}<0.01$ level. Figure 9 gives a visual comparison of the before and after results on speed and degree of wound repair.

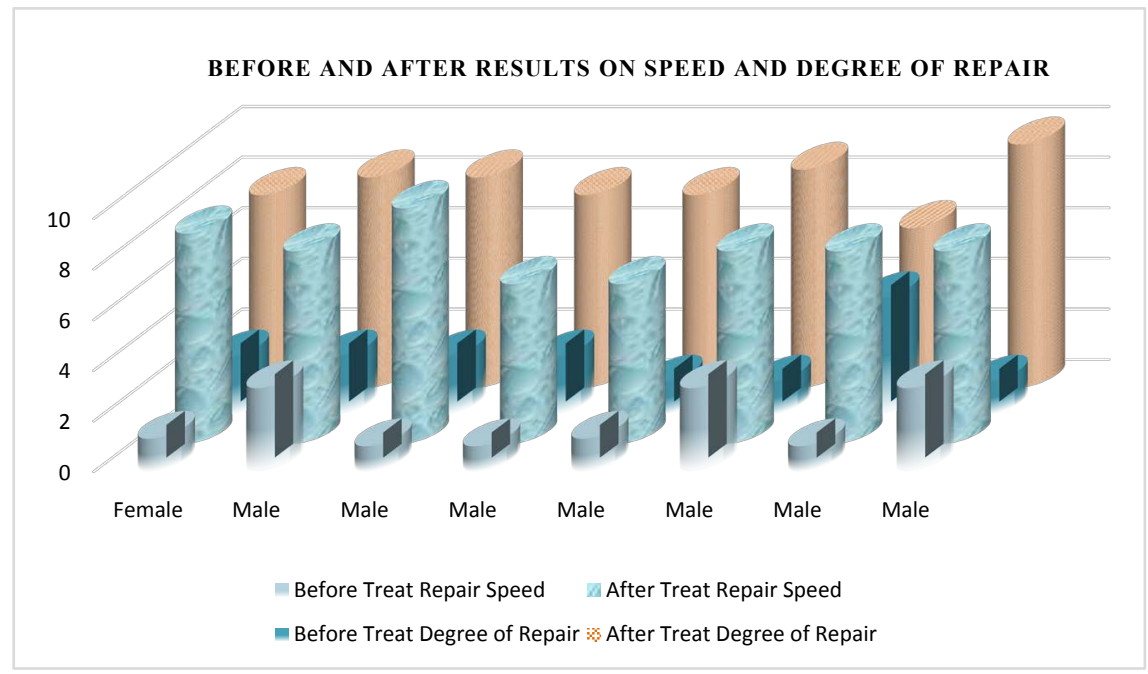

Figure 9. Degree and speed of healing before and after treatment for each subject.

Table 1. The mean average scores of the 3 judges for before and after treatment degree and speed of healing.

\begin{tabular}{|c|c|c|c|c|}
\hline & $\begin{array}{c}\text { BTSR Before } \\
\text { Treatment } \\
\text { Speed of Repair }\end{array}$ & $\begin{array}{c}\text { BTDR Before } \\
\text { Treatment } \\
\text { Degree of Repair }\end{array}$ & $\begin{array}{c}\text { ATSR After } \\
\text { Treatment } \\
\text { Speed of Repair }\end{array}$ & $\begin{array}{c}\text { ATDR After } \\
\text { Treatment } \\
\text { Degree of Repair }\end{array}$ \\
\hline & 1.3 & 2.3 & 8.3 & 7.6 \\
\hline & 3.3 & 2.3 & 7.6 & 8.3 \\
\hline & 1 & 2.3 & 9.3 & 8.3 \\
\hline & 1 & 2.3 & 6.3 & 7.6 \\
\hline & 1.3 & 1.3 & 6.3 & 7.6 \\
\hline & 3.3 & 1.3 & 7.6 & 8.6 \\
\hline & 1 & 4.6 & 7.6 & 6.3 \\
\hline & 3.3 & 1.3 & 7.6 & 9.6 \\
\hline $\begin{array}{c}\text { Total Mean } \\
\text { Average }\end{array}$ & 3.4 & 2.21 & 7.57 & 7.98 \\
\hline
\end{tabular}




\section{Discussion}

The results of this clinical trial indicated age-independent wound repair in our eight $28-86$ years old adult subjects of different ethnicities. The number of treatments required for skin repair was related to the chronicity and severity of the lesion, with more chronic severe lesions requiring more treatments irrespective of the subject's age. Subjects were monitored for at least one year after treatment, confirming the absence of reoccurrence. Our results were consistent with previous research using ultra-low microcurrents demonstrating accelerated wound healing, including diabetic foot lesions, where age was not a factor.

Age-independent wound repair seems to defy a number of aging theories postulating inevitable decline and irreversible inflammation. It directly contradicts the concept of "inflammaging" [62], which postulates a slower healing with age due to immune insufficiency, accumulative oxidative stress, increased inflammation and disrupted cell communications predisposing the body with inappropriate levels of growth factors and connexins. We interpreted our results as the outcome of ultra-low energies targeting molecular mechanisms which have the inherent capacity to reverse their paths from injury to self-restoration as seen in the anti-oxidant electron donation that transforms free radicals into stable molecules. The ultra-low energy nanotechnology used is based on the premise that electrons control the gates of potassium, sodium and calcium ion channels at energies below thermal noise, thus allowing the flow of electrons into the system, hindering inflammation by free radicals' elimination, while possibly, reinstating balance in damaged or over-excited signalling networks. If such electron-driven transformations truly represent a series of molecular time-reversal processes as we hypothesize, it is possible that ultra-low energies may be able to mobilize a number of other inherent time-reversal mechanisms of the body's cellular machines, repairing the body with the same speed and efficiency at any adult age. The validation of such a hypothesis by future research may have a great impact in several areas of regenerative and possibly preventive medicine.

Our sample was small and heterogeneous, including a large variety of skin lesions and aetiologies. Additionally, we did not have a placebo group, and we did not compare the experimental treatment with other methodologies. Our primary goal, however, was to draw attention to the unrealised potential of ultra-low energy technologies in treating dysfunctional tissue, so they can be more widely used and explored by research teams and clinicians treating hard to heal skin lesions.

\section{Acknowledgements}

The authors would like to thank Dr. William Stewart for his electronic research on this new low energy technology.

\section{Funding Sources}

This project was not been funded by an outside source or institution. 


\section{Conflicts of Interest}

The authors declare no conflicts of interest regarding the publication of this paper.

\section{References}

[1] Wells, A., Nuschke, A. and Yates, C. (2015) Skin Tissue Repair: Matrix Microenvironmental Influences. Matrix Biology, 49, 25-36.

https://www.ncbi.nlm.nih.gov/pubmed/11976459 https://doi.org/10.1016/j.matbio.2015.08.001

[2] Grieb, G., Steffens, G., Pallua, N., Bernhagen, J. and Bucala, R. (2011) Circulating Fibrocytes-Biology and Mechanisms in Wound Healing and Scar Formation. International Review of Cell and Molecular Biology, 291, 1-19. https://doi.org/10.1016/B978-0-12-386035-4.00001-X

[3] Redd, M., Cooper, L., Wood, W., Stramer, B. and Martin, P.N. (2004) Wound Healing and Inflammation: Embryos Reveal the Way to Perfect Repair. Philosophical Transactions of the Royal Society of London. Series B, Biological Sciences, 359, 777-784. https://www.ncbi.nlm.nih.gov/pmc/articles/PMC1693361 https://doi.org/10.1098/rstb.2004.1466

[4] Grose, R., Harris, B.S., Cooper, L., Topilko, P. and Martin, P. (2002) Immediate Early Genes krox-24 and krox-20 Are Rapidly Upregulated after Wounding in the Embryonic and Adult Mouse. Developmental Dynamics, 223, 371-378.

https://www.ncbi.nlm.nih.gov/pubmed/11891986 https://doi.org/10.1002/dvdy.10064

[5] Shaw, T. and Martin, P. (2009) Epigenetic Reprogramming during Wound Healing: Loss of Polycomb-Mediated Silencing May Enable Upregulation of Repair Genes. EMBO Reports, 10, 881-886. https://www.ncbi.nlm.nih.gov/pubmed/19575012 https://doi.org/10.1038/embor.2009.102

[6] Wong, V.W., Rustad, K.C., Akaishi, S., Sorkin, M., Glotzbach, J.P., Januszyk, M., Nelson, E.R., Levi, K., Paterno, J., Vial, I.N., Kuang, A.A., Longaker, M.T. and Gurtner, G.C. (2011) Focal Adhesion Kinase Links Mechanical Force to Skin Fibrosis via Inflammatory Signaling. Nature Medicine, 18, 148-152.

https://www.ncbi.nlm.nih.gov/pubmed/22157678 https://doi.org/10.1038/nm.2574

[7] Sasaki, M., Abe, R., Fujita, Y., Ando, S., Inokuma, D. and Shimizu, H. (2008) Mesenchymal Stem Cells Are Recruited into Wounded Skin and Contribute to Wound Repair by Transdifferentiation into Multiple Skin Cell Type. The Journal of Immunology, 180, 2581-2587. https://doi.org/10.4049/jimmunol.180.4.2581

[8] Lucas, T., Waisman, A., Ranjan, R., Roes, J., Krieg, T., Müller, W., Roers, A. and Eming, S.A. (2010) Differential Roles of Macrophages in Diverse Phases of Skin Repair. The Journal of Immunology, 184, 3964-3977.

https://www.ncbi.nlm.nih.gov/pubmed/20176743 https://doi.org/10.4049/jimmunol.0903356

[9] Martin, P. and Lebovich, J. (2005) Inflammatory Cells during Wound Repair: The Good, the Bad and the Ugly. Trends in Cell Biology, 15, 599-607.

https://pubmed.ncbi.nlm.nih.gov/16202600 https://doi.org/10.1016/j.tcb.2005.09.002

[10] Willenborg, S., Eckes, B., Brinckmann, J., Krieg, T., Waisman, A., Hartmann, K., Roers, A. and Eming, S.A. (2014) Genetic Ablation of Mast Cells Redefines the Role of Mast Cells in Skin Wound Healing and Bleomycin-Induced Fibrosis. Journal of 
Investigative Dermatology, 134, 2005-2015.

https://www.ncbi.nlm.nih.gov/pubmed/24406680

https://doi.org/10.1038/jid.2014.12

[11] Adzick, N.S., Harrison, M.R., Glick, P.L., Beckstead, J.H., Villa, R.L., Scheuenstuhl, H. and Goodson, W.H. (1985) Comparison of Foetal, New-Born, and Adult Wound Healing by Histologic, Enzyme-Histochemical, and Hydroxyproline Determinations. Journal of Pediatric Surgery, 20, 315-319.

https://www.ncbi.nlm.nih.gov/pubmed/4045654 https://doi.org/10.1016/S0022-3468(85)80210-4

[12] Ferguson, M.W. and O'Kane, S. (2004) Scar-Free Healing: From Embryonic Mechanisms to Adult Therapeutic Intervention. Philosophical Transactions of the Royal Society of London. Series B, Biological Sciences, 359, 839-850.

https://www.ncbi.nlm.nih.gov/pmc/articles/PMC1693363

https://doi.org/10.1098/rstb.2004.1475

[13] Brem, H., Stojadinovic, O., Diegelmann, R.F., Entero, H., Lee, B., Pastar, I., Golinko, M., Rosenberg, H. and Tomic-Canic, M. (2007) Molecular Markers in Patients with Chronic Wounds to Guide Surgical Debridement. Molecular Medicine, 13, 30-39. https://www.ncbi.nlm.nih.gov/pubmed/17515955

https://doi.org/10.2119/2006-00054.Brem

[14] Demidova-Rice, T., Hamblin, M. and Herman, I. (2012) Acute and Impaired Wound Healing: Pathophysiology and Current Methods for Drug Delivery, Part 1: Normal and Chronic Wounds: Biology, Causes, and Approaches to Care. Advances in Skin \& Wound Care, 25, 304-314.

https://www.ncbi.nlm.nih.gov/pmc/articles/PMC3428147 https://doi.org/10.1097/01.ASW.0000416006.55218.d0

[15] Shih, B. and Bayat, A. (2010) Genetics of Keloid Scarring. Archives of Dermatological Research, 302, 319-339. https://www.ncbi.nlm.nih.gov/pubmed/20130896 https://doi.org/10.1007/s00403-009-1014-y

[16] Alster, T.S. and Tanzi, E.L. (2003) Hypertrophic Scars and Keloids. Etiology and Management. American Journal of Clinical Dermatology, 4, 235-243.

https://www.ncbi.nlm.nih.gov/pubmed/12680802 https://doi.org/10.2165/00128071-200304040-00003

[17] Alexander, G., Marneros, J., Norris, E.C. and Olsen, B. (2001) Clinical Genetics of Familial Keloids. Arch Dermatologist, 137, 1429-1434. https://doi.org/10.1001/archderm.137.11.1429

[18] Moustafa, M.F., Abdel-Fattah, M.A. and Abdel-Fattah, D.C. (1975) Presumptive Evidence of the Effect of Pregnancy Estrogens on Keloid Growth. Case Report. Plastic and Reconstructive Surgery, 56, 450-453. https://doi.org/10.1097/00006534-197510000-00019

[19] Leszczynski, R., da Silva, C.A.P., Kudzynski, U. and da Silva, E.M.K. (2015) Laser Therapy for Treating Hypertrophic and Keloid Scars. Cochrane Systematic Review Intervention Protocol. https://doi.org/10.1002/14651858.CD011642

[20] Gupta, S. and Sharma, V.K. (2011) Standard Guidelines of Care: Keloids and Hypertrophic Scars. Indian Journal of Dermatology, Venereology, and Leprology, 77, 94-100. https://doi.org/10.4103/0378-6323.74968 http://www.ijdvl.com/article.asp?issn=0378-6323;year=2011; volume=77;issue =1; spa ge $=94$; epage $=100$; aulast $=$ Gupta

[21] Juckett, G. and Hartman-Adams, H. (2009) Management of Keloids and Hypertrophic Scars. American Family Physician, 80, 253-260. https://www.aafp.org/afp/2009/0801/p253.html 
[22] Trace, A.P., Enos, C.W., Mantel, A. and Harvey, V.M. (2016) Keloids and Hypertrophic Scars: A Spectrum of Clinical Challenges. American Journal of Clinical Dermatology, 17, 201-223. https://www.ncbi.nlm.nih.gov/pubmed/26894654 https://doi.org/10.1007/s40257-016-0175-7

[23] Akaishi, S., Koike, S., Dohi, T., Kobe, K., Hyakusoku, H. and Ogawa, R. (2012) Nd:YAG Laser Treatment of Keloids and Hypertrophic Scars. Eplasty, 12, e1. https://www.ncbi.nlm.nih.gov/pmc/articles/PMC3258100

[24] Huang, L., Wong, Y.P., Cai, Y.J., et al. (2010) Low-Dose 5-Fluorouracil Induces Cell Cycle G2 Arrest Andapoptosis in Keloid Fibroblasts. British Journal of Dermatology, 163, 1181-1195. https://www.ncbi.nlm.nih.gov/pubmed/20633010 https://doi.org/10.1111/j.1365-2133.2010.09939.x

[25] Gupta, S. and Kalra, A. (2002) Efficacy and Safety of Intralesional 5-Fluorouracil in the Treatment of Keloids. Dermatology, 204, 130-132.

https://www.ncbi.nlm.nih.gov/pubmed/11937738 https://doi.org/10.1159/000051830

[26] Saha, A.K. and Mukhopadhyay, M. (2012) A Comparative Clinical Study on Role of 5-Flurouracil Versustriamcinolone in the Treatment of Keloids. Indian Journal of Surgery, 74, 326-329. https://www.ncbi.nlm.nih.gov/pmc/articles/PMC3444598 https://doi.org/10.1007/s12262-011-0399-y

[27] Kajagar, B.M., Godhi, A.S., Pandit, A. and Khatri, S. (2012) Efficacy of Low-Level Laser Therapy on Wound Healing in Patients with Chronic Diabetic Foot Ulcers-A Randomised Control Trial. Indian Journal of Surgery, 74, 359-363.

https://www.ncbi.nlm.nih.gov/pmc/articles/PMC3477409 https://doi.org/10.1007/s12262-011-0393-4

[28] Beckerman, H., de Bie, R.A., Bouter, L.M., De Cuyper, H.J. and Oostendorp, R.A.B. (1992) The Efficacy of Laser Therapy for Musculoskeletal and Skin Disorders: A Criteria-Based Meta-Analysis of Randomized Clinical Trials. Physical Therapy, 72, 483-491. https://www.ncbi.nlm.nih.gov/pubmed/1409881 https://doi.org/10.1093/ptj/72.7.483

[29] Nuccitelli, R. (1992) Endogenous Ionic Currents and CE Electric Fields in Multicellular Animal Tissues. Bioelectromagnetics, 1, 147-157. https://doi.org/10.1002/bem.2250130714

[30] Zhao, M., Bai, H., Wang, E., Forrester, J.V. and McCaig, C.D. (2004) Electrical Stimulation Directly Induces Pre-Angiogenic Responses in Vascular Endothelial Cells by Signalling through VEGF Receptors. Journal of Cell Science, 117, 397-405. https://jcs.biologists.org/content/117/3/397.full https://doi.org/10.1242/jcs.00868

[31] Kanno, S., Oda, N., et al. (1999) Establishment of a Simple and Practical Procedure Applicable to Therapeutic Angiogenesis. Circulation, 99, 2682-2687. https://doi.org/10.1161/01.CIR.99.20.2682

[32] Linderman, J.R., Kloehn, M.R. and Greene, A.S. (2000) Development of an Implantable Muscle Stimulator: Measurement of Stimulated Angiogenesis and PostStimulus Vessel Regression. Microcirculation, 77, 119-128. https://doi.org/10.1080/sj.mn.7300100

[33] Coronel, R., Wilms-Schopman, F.J., Opthof, T., Van Cappele, F.J. and Jance, M.J. (1991) Injury Current and Gradients of Diastolic Stimulation Threshold, TQ Potential, and Extracellular Potassium Concentration during Acute Regional Ischemia in the Isolated Perfused Pig Heart. Circulation Research, 68, 1241-1249.

https://doi.org/10.1161/01.RES.68.5.1241 
[34] Cheng, N., Van Hoof, H., Bockx, E., Hoogmartens, M.J., Mulier, J.C., De Dijcker, F.J., Sansen, W.M. and De Loecker, W. (1982) The Effects of Electric Currents on ATP Generation, Protein Synthesis, and Membrane Transport of Rat Skin. Clinical Orthopaedics and Related Research, 171, 264-272.

https://www.ncbi.nlm.nih.gov/pubmed/7140077 https://doi.org/10.1097/00003086-198211000-00045

[35] Todd, I., Clothier, R.H., Huggins, M.L., Patel, N., Searle, K.C., Jeyarajah, S., Pradel, L. and Lacey, K.L. (2001) Electrical Stimulation of Transforming Growth Factor-Beta 1 Secretion by Human Dermal Fibroblasts and the U937 Human Monocytic Cell Line. Alternatives to Laboratory Animals, 29, 693-701.

https://www.ncbi.nlm.nih.gov/pubmed/11709043

https://doi.org/10.1177/026119290102900611

[36] Poltawski, L. and Watson, T. (2009) Bioelectricity and Microcurrent Therapy for Tissue Healing-A Narrative Review. Journal of Physical Therapy Reviews, 14, 104-114. https://doi.org/10.1179/174328809X405973

[37] Wishing, P.G., Habrom, A.D., Zehnder, T.M., Friedli, S. and Blatti, M. (2013) Wireless Micro Current Stimulation-An Innovative Electrical Stimulation Method for the Treatment of Patients with Leg and Diabetic Foot Ulcers. International Wound Journal, 12, 693-698. https://doi.org/10.1111/iwj.12204

[38] Lee, B.Y., Al-Waili, N., Stubbs, D., Wendell, K., Butler, G., Al-Waili, T. and Al-Waili, A. (2010) Ultra-Low Microcurrent in the Management of Diabetes Mellitus, Hypertension and Chronic Wounds: Report of Twelve Cases and Discussion of Mechanism of Action. International Journal of Medical Sciences, 7, 29-35.

https://www.ncbi.nlm.nih.gov/pmc/articles/PMC2792735 https://doi.org/10.7150/ijms.7.29

[39] Goossens, V., De Vos, K., Vercammen, D., et al. (1999) Redox Regulation of TNF Signaling. Bio Factors, 10, 145-156. https://doi.org/10.1002/biof.5520100210 https://www.ncbi.nlm.nih.gov/pubmed/10609876

[40] Kumar and Pandey, A.K. (2015) Free Radicals: Health Implications and Their Mitigation by Herbals. British Journal of Medicine and Medical Research, 7, 438-457. https://www.academia.edu/15709907/Free_Radicals_Health_Implications_and_thei r_Mitigation_by_Herbals https://doi.org/10.9734/BJMMR/2015/16284

[41] Franceschi, C., Garagnani, P., Parini, P., Giuliani, C. and Santoro, A. (2018) Inflammaging: A New Immune-Metabolic Viewpoint for Age-Related Diseases. $\mathrm{Na}$ ture Reviews Endocrinology, 14, 576-590.

https://www.nature.com/articles/s41574-018-0059-4\#auth-1 https://doi.org/10.1038/s41574-018-0059-4

[42] Oschman, J.L. (2005) Energy and the Healing Response. Journal of Bodywork and Movement Therapies, 9, 3-15. https://doi.org/10.1016/S1360-8592(03)00092-5

[43] Ralston, W.P. (2005) Electron-Gated Ion Channels: With Amplification by $\mathrm{NH}_{3}$ Inversion Resonance. Institution of Engineering and Technology, Science, $190 \mathrm{p}$. https://books.google.com.hk/books/about/Electron_Gated_Ion_Channels.html?id= $\underline{\text { zaAkQhkZP0C\&source }=\mathrm{kp} \_c o v e r \& \text { redir_esc }=\mathrm{y}}$

[44] Ishida, Y., Agata, Y., Shibahara, K. and Honjo, T. (1992) Induced Expression of PD-1, a Novel Member of the Immunoglobulin Gene Superfamily, upon Programmed Cell Death. The EMBO Journal, 11, 3887-3895.

https://www.ncbi.nlm.nih.gov/pubmed/1396582 https://doi.org/10.1002/j.1460-2075.1992.tb05481.x

[45] Leach, D.R., Krummel, M.F. and Allison, J.P. (1996) Enhancement of Antitumor 
Immunity by CTLA-4 Blockade. Science, 271, 1734-1736.

https://www.ncbi.nlm.nih.gov/pubmed/8596936

https://doi.org/10.1126/science.271.5256.1734

[46] Nishimura, H., Nose, M., Hiai, H., Minato, N. and Honjo, T. (1999) Development of Lupus-Like Autoimmune Diseases by Disruption of the PD-1 Gene Encoding an ITIM Motif-Carrying Immunoreceptor. Immunity, 11, 141-151.

https://www.ncbi.nlm.nih.gov/pubmed/10485649

https://doi.org/10.1016/S1074-7613(00)80089-8

[47] Freeman, G.J., Long, A.J., Iwai, Y., Bourque, K., Chernova, T., Nishimura, H., Fitz, L.J., Malenkovich, N., Okazaki, T., Byrne, M.C., Horton, H.F., Fouser, L., Carter, L., Ling, V., Bowman, M.R., Carreno, B.M., Collins, M., Wood, C.R. and Honjo, T. (2000) Engagement of the PD-1 Immunoinhibitory Receptor by a Novel B7 Family Member Leads to Negative Regulation of Lymphocyte Activation. Journal of Experimental Medicine, 192, 1027-1034. https://doi.org/10.1084/jem.192.7.1027 https://www.ncbi.nlm.nih.gov/pubmed/11015443

[48] Hodi, F.S., Mihm, M.C., Soiffer, R.J., Haluska, F.G., Butler, M., Seiden, M.V., Davis, T., Henry-Spires, R., MacRae, S., Willman, A., Padera, R., Jaklitsch, M.T., Shankar, S., Chen, T.C., Korman, A., Allison, J.P. and Dranoff, G. (2003) Biologic Activity of Cytotoxic T Lymphocyte-Associated Antigen 4 Antibody Blockade in Previously Vaccinated Metastatic Melanoma and Ovarian Carcinoma Patients. Proceedings of the National Academy of Sciences of the United States of America, 100, 4712-4717. https://www.ncbi.nlm.nih.gov/pubmed/12682289 https://doi.org/10.1073/pnas.0830997100

[49] Iwai, Y., Terawaki, S. and Honjo, T. (2005) PD-1 Blockade Inhibits Hematogenous Spread of Poorly Immunogenic Tumor Cells by Enhanced Recruitment of Effector T Cells. International Immunology, 17, 133-144. https://www.ncbi.nlm.nih.gov/pubmed/15611321 https://doi.org/10.1093/intimm/dxh194

[50] Rothman, J.E., Schekman, R.W. and Südhof, T.C. (2013) Nobel Prize in Physiology or Medicine 2013 Machinery Regulating Vesicle Traffic, a Major Transport System in Our Cells. https://www.nobelprize.org/prizes/medicine/2013/summary

[51] Novick, P. and Schekman, R. (1979) Secretion and Cell-Surface Growth Are Blocked in a Temperature-Sensitive Mutant of Saccharomyces cerevisiae. Proceedings of the National Academy of Sciences of the United States of America, 76, 1858-1862. https://www.ncbi.nlm.nih.gov/pmc/articles/PMC383491 https://doi.org/10.1073/pnas.76.4.1858

[52] Balch, W.E., Dunphy, W.G., Braell, W.A. and Rothman, J.E. (1984) Reconstitution of the Transport of Protein between Successive Compartments of the Golgi Measured by the Coupled Incorporation of N-Acetylglucosamine. Cell, 39, 405-416. https://www.ncbi.nlm.nih.gov/pubmed/6498939 https://doi.org/10.1016/0092-8674(84)90019-9

[53] Kaiser, C.A. and Schekman, R. (1990) Distinct Sets of SEC Genes Govern Transport Vesicle Formation and Fusion Early in the Secretory Pathway. Cell, 61, 723-733. https://www.ncbi.nlm.nih.gov/pubmed/2188733 https://doi.org/10.1016/0092-8674(90)90483-U

[54] Perin, M.S., Fried, V.A., Mignery, G.A., Jahn, R. and Südhof, T.C. (1990) Phospholipid Binding by a Synaptic Vesicle Protein Homologous to the Regulatory Region of Protein Kinase C. Nature, 345, 260-263.

https://www.ncbi.nlm.nih.gov/pubmed/2333096 https://doi.org/10.1038/345260a0 
[55] Sollner, T., Whiteheart, W., Brunner, M., Erdjument-Bromage, H., Geromanos, S., Tempst, P. and Rothman, J.E. (1993) SNAP Receptor Implicated in Vesicle Targeting and Fusion. Nature, 362, 318-324.

https://www.ncbi.nlm.nih.gov/pubmed/8455717 https://doi.org/10.1038/362318a0

[56] Hata, Y., Slaughter, C.A. and Südhof, T.C. (1993) Synaptic Vesicle Fusion Complex Contains unc-18 Homologue Bound to Syntaxin. Nature, 366, 347-351.

https://www.ncbi.nlm.nih.gov/pubmed/8247129 https://doi.org/10.1038/366347a0

[57] Araque, A. and Navarrete, M. (2010) Glial Cells in Neuronal Network Function. Philosophical Transactions of the Royal Society of London. Series B, Biological Sciences, 365, 2375-2381. https://www.ncbi.nlm.nih.gov/pmc/articles/PMC2894949 https://doi.org/10.1098/rstb.2009.0313

[58] Chaban, V.V., Cho, T., Reid, C.B. and Norris, K.C. (2013) Physically Disconnected Non-Diffusible Cell-to-Cell Communication between Neuroblastoma SH-SY5Y and DRG Primary Sensory Neurons. American Journal of Translational Research, 5, 69-79. https://www.ncbi.nlm.nih.gov/pmc/articles/PMC3560476

[59] Pastar, I., Stojadinovic, O., Krzyzanowska, A., Barrientos, S., Stuelten, C., Zimmerman, K., Blumenberg, M., Brem, H. and Tomic-Canic, M. (2010) Attenuation of the Transforming Growth Factor Beta-Signalling Pathway in Chronic Venous Ulcers. Molecular Medicine, 16, 92-101.

https://www.ncbi.nlm.nih.gov/pmc/articles/PMC2804290 https://doi.org/10.2119/molmed.2009.00149

[60] Naghibi, M., Smith, R.P., Baltch, A.L., Gates, S.A., Wu, D.H., Hammer, M.C. and Michelsen, P.B. (1987) The Effect of Diabetes Mellitus on Chemotactic and Bactericidal Activity of Human Polymorphonuclear Leukocytes. Diabetes Research and Clinical Practice, 4, 27-35. https://www.ncbi.nlm.nih.gov/pubmed/3121272 https://doi.org/10.1016/S0168-8227(87)80030-X

[61] Apelqvist, J., Larsson, J. and Agardh, C.D. (1992) Medical Risk Factors in Diabetic Patients with Foot Ulcers and Severe Peripheral Vascular Disease and Their Influence on Outcome. Journal of Diabetic Complications, 6, 167-174.

https://europepmc.org/article/med/1472742 https://doi.org/10.1016/1056-8727(92)90032-G

[62] Ferrucci, L. and Fabbri, E. (2018) Inflammageing: Chronic Inflammation in Ageing, Cardiovascular Disease, and Frailty. Nature Reviews Cardiology, 15, 505-522.

https://www.nature.com/articles/s41569-018-0064-2

https://doi.org/10.1038/s41569-018-0064-2 